\title{
Instrumentos da Política Nacional do Meio Ambiente: como se encontram após 40 anos da promulgação?
}

\author{
National Environment Policy Instruments: how are they doing after 40 years of promulgation? \\ Instrumentos de la Política Nacional del Medio Ambiente: ¿cómo se encuentran después de 40 años
} de promulgación?

\author{
Marco Bruno Xavier Valadão \\ ORCID: https://orcid.org/0000-0002-5917-4940 \\ Universidade de Brasília, Brasil \\ E-mail: marcobrunovaladao@gmail.com \\ Fabiana Piontekowski Ribeiro \\ ORCID: https://orcid.org/0000-0002-5375-6368 \\ Universidade de Brasília, Brasil \\ E-mail: fabiana.ribeiro@unb.br \\ Maisa Isabela Rodrigues \\ ORCID: https://orcid.org/0000-0003-2654-8245 \\ Universidade de Brasília, Brasil \\ E-mail: maisarodrigues.eng@gmail.com \\ Alcides Gatto \\ ORCID: https://orcid.org/0000-0002-2663-9318 \\ Universidade de Brasília, Brasil \\ E-mail: alcidesgatto@unb.br
}

\begin{abstract}
Resumo
Até o início do século XX, a preocupação com o meio ambiente tinha um caráter remediador, e a prevenção começou a ser considerada apenas em meados do mesmo período. Visando o uso racional dos recursos naturais, no início da década de 1980 o Brasil promulgou a Lei n 6.938/81, que instituiu a Política Nacional do Meio Ambiente (PNMA) e criou o Sistema Nacional do Meio Ambiente (SISNAMA). Nesse contexto, estudo teve como objetivo apresentar o desenvolvimento da PNMA após quatro décadas de implantação. Focada exclusivamente no uso racional dos recursos naturais, esta Lei trouxe: definições, objetivos e princípios. No entanto, estabelecer instrumentos para a implementação dessa política foi a proposta mais ousada e desafiadora até então. Assim, foram estabelecidos treze instrumentos que atualmente funciona como ferramentas na busca por uma economia pautada no desenvolvimento econômico sustentável. A nova Constituição de 1988, Leis Complementares Resoluções Conselho Nacional do Meio Ambiente, Instruções Normativas e Decretos Ministeriais regulamentaram esses instrumentos. A situação atual de todos esses dispositivos foi a base argumentativa que sustentou o posicionamento deste trabalho. A necessidade de atualização, a atuação frágil do poder público e a impunidade diante de condutas lesivas são fatos que comprometem a atuação dessas ferramentas. Ressalta-se que, mesmo após quarenta anos, há muito a ser feito, principalmente pelo caráter dinâmico que envolve o uso dos recursos ambientais.
\end{abstract}

Palavras-chave: Legislação ambiental; Licenciamento ambiental; Zoneamento ambiental; Avaliação de impacto ambiental.

\begin{abstract}
In the early twentieth century concern for the environment had a remedial character, the prevention only started to be considered only in the middle of the last century. Aimed a rational use of natural resources in the beginning of the 80's Brazil enactment of the Law number 6.938/81 that institutes the National Environment Policy this low also created the National Environment System. Focus exclusive on the rational use of natural resources, this Law brought: definitions, objectives and principles. However, establishing instruments for the implementation of this policy was the most daring and challenging proposal so far. Thus, thirteen instruments were established that would function as tools in the search for an economy based on sustainable economic development. The new Constitution of 1988, Complementary Laws Resolutions National Environment Council, Normative Instructions and Ministerial Decrees regulated these instruments. The current situation of all these devices was the argumentative basis that supported the position of this work. The need for updating, the fragile performance of the public authorities, and impunity in the face of conduct harmful are facts that compromise the action of these tools. It is noteworthy that, even after forty years, there is much to be done, mainly due to the dynamic character that involves the use of environmental resources.
\end{abstract}

Keywords: Environmental laws; Environmental licensing; Environmental zoning; Environmental impact assessment. 


\begin{abstract}
Resumen
A principios del siglo $\mathrm{XX}$, la preocupación por el medio ambiente tenía un carácter remediador, y la prevención comenzó a ser considerada recién a mediados del mismo período. Con el objetivo de la utilización racional de los recursos naturales, a principios de la década de 1980, Brasil promulgó la Ley nº 6.938/81, que estableció la Política Nacional Ambiental (PNMA) y creó el Sistema Nacional Ambiental (SISNAMA). En ese contexto, el estudio tuvo como objetivo presentar el desarrollo del PNMA después de cuatro décadas de implementación. Con el enfoque exclusivo en el uso racional de los recursos naturales, esta Ley trajo: definiciones, objetivos y principios. Sin embargo, establecer instrumentos para la implementación de esta política fue, sin duda, la propuesta más osada y desafiante de la Política Nacional del Medio Ambiente. Así, se establecieron trece instrumentos que funcionarían como herramientas en la búsqueda de una economía basada en el desarrollo económico sostenible. La nueva Constitución Federal de 1988, Leyes Complementarias, Resoluciones del Consejo Nacional del Medio Ambiente, Instructivos Normativos y Ordenanzas Ministeriales que reglamentaron estos instrumentos. La situación actual de todos estos dispositivos fue la base argumental que sustentaba la posición de este trabajo. La necesidad de actualización, la actuación frágil de los poderes públicos, la impunidad ante conductas nocivas para el medio ambiente son algunos de los factores que comprometen la acción de estas herramientas. Es de destacar que, mismo después de cuarenta años, queda mucho por hacer, principalmente por el carácter dinámico que implica el uso de los recursos ambientales.
\end{abstract}

Palabras clave: Legislación ambiental; Licencia ambiental; Zonificación ambiental; Evaluación de impacto ambiental.

\title{
1. Introdução
}

O efeito das ações humanas sobre o meio ambiente, não só no mundo, mas também no Brasil, foi norteado pelo aumento populacional, que historicamente, gerou pressão sobre recursos naturais e, consequentemente, aumentou os riscos de que eventos ambientais catastróficos ocorressem como desmatamento, desertificação, ocupação urbana desordenada, extinção de espécies e biodiversidade, produção de resíduos, poluição da água e mudanças climáticas são impactos negativos e que demandavam normatização (Novo, 2017).

Essa demanda não era digna de preocupação no período da Revolução Industrial, em que as medidas de controle ambiental eram simplesmente paliativas. As estratégias de gestão eram utilizadas simplesmente com intuito de remediar problemas que poderiam ser evitados. Entretanto, em meados do século XX, o movimento ambientalista ganhou destaque e pesquisadores como Rachel Carson, que por meio de seu livro Primavera Silenciosa de 1962, estabeleceu um contraponto às consequências advindas da Revolução Verde.

O relatório do Clube de Roma, de 1968, e a Conferência das Nações Unidas sobre o Meio Ambiente Humano, realizada em Estocolmo em 1972, foram os primeiros eventos que trataram diretamente de questões relacionadas à degradação do meio ambiente. A Conferência de Estocolmo é considerada um marco na tentativa de alinhar a relação do homem com o meio ambiente e ainda iniciou a busca pelo equilíbrio entre o desenvolvimento econômico e a redução da degradação ambiental, que evoluiria para o conceito de desenvolvimento sustentável.

Esse encontro estabeleceu a Comissão Mundial sobre Meio Ambiente e Desenvolvimento liderado pela Primeira Ministra da Noruega, Gro Harlem Brundtland e que em 1987 apresentou o relatório Nosso Futuro Comum. O documento dispunha da expressão "desenvolvimento sustentável" como uma alternativa de garantir as necessidades das gerações atuais sem, no entanto, comprometer a capacidade das gerações futuras (Comissão de Brundtland, 1991).

No Brasil, essa preocupação tomou forma a partir da década de 70 com a exigência, por parte do Banco Mundial, de estudo de impacto ambiental para a construção de barragens para hidrelétricas (Sánchez, 2013). Entretanto, nosso país não possuía normas legais, que contemplassem, por exemplo, os princípios ambientais da prevenção e precaução. Dessa maneira os estudos de impacto ambiental não eram analisados e deliberados por parte do poder público.

Em 1981, um modelo de política ambiental foi inserido no Brasil. Com a aprovação pelo Congresso Nacional da Lei $\mathrm{n}^{\circ}$ 6.938/1981 (Brasil, 1981), foi instituída a Política Nacional do Meio Ambiente (PNMA). Antunes (2010) destacou que a PNMA deveria ser compreendida como o conjunto dos instrumentos legais, técnicos, científicos, políticos e econômicos 
destinados à promoção do desenvolvimento sustentável da sociedade e economia brasileiras. A PNMA teve como objeto de estudo a qualidade ambiental propícia à vida das presentes e futuras gerações (Sirvinskas, 2018). A propositura desse dispositivo legal mostrou que a preocupação com o meio ambiente não era exclusiva de países ricos. Nações em desenvolvimento e que passavam por processo de redemocratização, como o Brasil, também legitimaram essa demanda ambiental (Morais \& Freitas, 2020).

A PNMA trouxe no art. $9^{\circ}$ sua maior pretensão no âmbito ambiental. Foram elencados treze (13) instrumentos com o objetivo de colocar em prática a política ambiental do Brasil. Alguns instrumentos foram devidamente regulamentados por meio de leis complementares, outros passaram a constar em instruções normativas, ou ainda carecem de regulamentações mais incisivas. Dessa maneira, o objetivo do presente trabalho foi argumentar a respeito da situação de todos os instrumentos da PNMA, destacando avanços normativos, potencialidades e perspectivas após quatro décadas de sua implantação.

\section{Metodologia}

Foi realizado um vasto levantamento teórico a respeito do estado atual de cada um dos 13 (treze) instrumentos que compões a PNMA. Promulgação de atos normativos tais como: leis complementares, instruções normativas, programas e resoluções do Conselho Nacional do Meio Ambiente (CONAMA) foram amplamente consultados com o intuito de sustentar a argumentação defendida para cada instrumento da PNMA.

\section{Resultados e Discussão}

Treze são os instrumentos estabelecidos na Lei n ${ }^{\circ}$ 6.938/1981, mais especificamente no art. $9^{\circ}$. É importante ressaltar que não se confundem com os instrumentos materiais previstos nos incisos I a VII, do $\S 1^{\circ}$, do art. 225 da Constituição Federal (Brasil, 1988), nem com os instrumentos processuais, legislativos ou administrativos (Sirvinskas, 2018). O principal escopo dessas ferramentas é cumprir os objetivos estabelecidos no art. $4^{\circ}$ da PNMA (Sirvinskas, 2018).

Sendo assim, os instrumentos da PNMA, de acordo com os incisos I a XIII, do art. $9^{\circ}$, são:

I - o estabelecimento de padrões de qualidade ambiental; II - o zoneamento ambiental; III - a avaliação de impactos ambientais; IV - o licenciamento e a revisão de atividades efetiva ou potencialmente poluidoras; V - os incentivos à produção e instalação de equipamentos e a criação ou absorção de tecnologia, voltados para a melhoria da qualidade ambiental; VI - a criação de espaços territoriais especialmente protegidos pelo Poder Público federal, estadual e municipal, tais como áreas de proteção ambiental, de relevante interesse ecológico e reservas extrativistas; VII - o sistema nacional de informações sobre o meio ambiente; VIII - o Cadastro Técnico Federal de Atividades e Instrumentos de Defesa Ambiental; IX - as penalidades disciplinares ou compensatórias ao não cumprimento das medidas necessárias à preservação ou correção da degradação ambiental; X - a instituição do Relatório de Qualidade do Meio Ambiente, a ser divulgado anualmente pelo Instituto Brasileiro do Meio Ambiente e Recursos Naturais Renováveis - IBAMA; XI - a garantia da prestação de informações relativas ao Meio Ambiente, obrigando-se o Poder Público a produzi-las, quando inexistentes; XII - o Cadastro Técnico Federal de atividades potencialmente poluidoras e/ou utilizadoras dos recursos ambientais; e XIII - instrumentos econômicos, como concessão florestal, servidão ambiental, seguro ambiental e outros (Brasil, 1981).

\section{O estabelecimento de padrões de qualidade ambiental}

O estabelecimento de padrões de qualidade ambiental foi efetivado por resoluções editadas pelo Conselho Nacional do Meio Ambiente (CONAMA). O CONAMA foi estabelecido na PNMA como um órgão consultivo e deliberativo, com a finalidade de assessorar, estudar e propor, ao Conselho de Governo, diretrizes de políticas governamentais para o meio ambiente, recursos naturais e deliberar, no âmbito de sua competência, sobre normas e padrões compatíveis com o meio ambiente ecologicamente equilibrado e essencial à sadia qualidade de vida (Lei nº 6.938/1981, art. $6^{\circ}$, inciso II). A Resolução CONAMA 20/1986 (MMA, 1986), posteriormente alterada pela CONAMA 274/2000 (MMA, 2000) e revogada pela 
CONAMA 357/2005 (MMA, 2005), e que na sequência foi alterada pelas resoluções CONAMA 410/2009 (MMA, 2009) e CONAMA 430/2011 (MMA, 2011), que trataram da classificação e qualidade de águas superficiais.

A concentração de sal na água, que classifica os corpos d'água em: águas doces, salobras e salinas, também é definida por essa resolução. A criação de uma agência reguladora, a Agência Nacional de Águas (ANA) em 2000, buscou a manutenção de um padrão de qualidade dos recursos hídricos no país. Entretanto, tomando como referência a qualidade da água, o saneamento básico no Brasil ainda é bastante precário. Apenas 45,7\% dos domicílios têm acesso à rede de esgoto no Brasil, sendo que somente 30,5\% desse efluente é tratado (Santiago et al., 2016).

Quanto à qualidade do ar, a resolução CONAMA 491/2018 (MMA, 2018) tratou dos limites toleráveis de emissões e propôs um Plano de Controle de Emissões Atmosféricas. No entanto, a ausência de padrões mais rigorosos consiste em um sério problema de saúde pública, e a carência de dispositivos legais em conformidade com padrões internacionais também é um empecilho na efetividade desse instrumento (Da Silva \& Vieira, 2017).

\section{O zoneamento ambiental}

O ordenamento de locais específicos, para instalação de empreendimentos potencialmente poluidores, garante que centros urbanos sejam menos suscetíveis aos impactos ambientais provenientes de atividades industriais. Rosa (2018) afirma que o zoneamento ambiental é o produto final do Plano Diretor Ambiental, sendo representado por um mapa com a delimitação de zonas homogêneas compatíveis com determinado conjunto de diretrizes a serem seguidas pelos órgãos e entidades responsáveis pela gestão territorial.

Um ano antes da PNMA ser promulgada (1981), a Lei n ${ }^{\circ}$ 6.803/1980 (Brasil, 1980), dispôs sobre as diretrizes básicas para o zoneamento industrial nas áreas críticas de poluição. Ela estabeleceu que áreas críticas de poluição em ambiente urbano deveriam ser classificadas da seguinte maneira: zonas de uso estritamente industrial, zonas de uso predominantemente industrial e zonas de uso diversificado. Também foram definidas as zonas de reserva ambiental com o intuito de preservar áreas especiais com relevância cultural, paisagística e ecológica.

No âmbito mais genérico, buscando compatibilizar a execução de obras públicas e privadas com a proteção ambiental, o Decreto n 4.297/2002 (Brasil, 2002) estabeleceu critérios para o Zoneamento Ecológico-Econômico (ZEE) do Brasil. O ZEE determinou a geração de produtos e informações em escala nacional, macrorregional, estadual, regional e local com o intuito de auxiliar o Poder Público Federal. Também definiu critérios específicos de elaboração, conteúdo e publicidade das informações geradas.

O ZEE envolve diagnóstico e prognóstico sobre potencialidades e fragilidades regionais, em função dos recursos ambientais. A identificação dessas áreas visa limitar a utilização dos recursos, evitando danos ao meio ambiente (Barros et al., 2012). Esse ordenamento é de responsabilidade de todos os entes federativos, como estabeleceu a Lei Complementar no 140, de dezembro de 2011 (Brasil, 2011). A União ficou responsável pela elaboração do zoneamento ambiental em âmbito nacional e regional, e os estados pelo zoneamento em âmbito estadual em conformidade com diretrizes nacionais e regionais. Após quase dez anos, há muito trabalho a se fazer. No âmbito federal, apenas o MacroZEE da Amazônia Legal encontra-se normatizado, ainda que por meio de um decreto, e a grande maioria dos estados não possuem normatização e validação por parte do governo federal.

\section{A avaliação de impactos ambientais}

A Avalição de Impacto Ambiental (AIA) foi tema da primeira Resolução (01) publicada pelo CONAMA, em 1986 (MMA, 1986). Logo no primeiro artigo definiu-se impacto ambiental como "qualquer alteração das propriedades físicas, químicas e biológicas do meio ambiente, causada por qualquer forma de matéria ou energia resultante das atividades 
humanas". Nos incisos de I a V, ainda do primeiro artigo, foi descrita as possibilidades, de forma direta ou indireta, de alteração nos padrões: de saúde, segurança e bem-estar da população; atividades sociais e econômicas; biota; condições estéticas e sanitárias do meio ambiente e a qualidade dos recursos ambientais. Como a promulgação da Constituição de Federal em 1998 o Estudo de Impacto Ambiental (EIA) foi elevado à norma constitucional no respectivo inciso IV, parágrafo primeiro, do art. 225 (Brasil, 1988), que trata do direito ao meio ambiente ecologicamente equilibrado. Direito esse, considerado na doutrina constitucional como de terceira geração.

A AIA tornou-se uma condicionante do licenciamento ambiental e exigiu uma estruturação de órgãos ambientais em todos os estados da União, deste modo se define como um estudo de caráter prospectivo, antecipatório, prévio e preventivo (Sánchez, 2013) e coaduna com o princípio ambiental da prevenção. De acordo com CONAMA 01/1986 (Brasil, 1986), o EIA e o Relatório de Impacto Ambiental (RIMA) são os documentos submetidos aos órgãos ambientais.

O primeiro, de acordo com a resolução, consiste em um diagnóstico ambiental da área de influência do projeto e considera aspectos físicos, químicos, biológicos e socioeconômicos, bem como são exigidas definição de medidas mitigadoras e programas de monitoramento. O segundo é uma síntese dos resultados, em que são apresentadas alternativas tecnológicas, área de influência, mão-de-obra, provável emissão de efluentes, dentre outros. A resolução ainda previu a possibilidade da não realização de determinado projeto, evocando assim o princípio da precaução.

Mineração, agropecuária e hidroelétricas são exemplos de atividades condicionadas à AIA, pois os impactos transcendem os limites locais e exigem estudos mais detalhados, com medidas mitigatórias. Entretanto, tragédias como as de Mariana e Brumadinho, ambas no estado de Minas Gerais, revelaram a ineficiência de órgãos estaduais em fiscalizar grandes corporações. Lopes \& Ribeiro (2016) afirmam que propostas com caráter "compensatório", como o patrocínio de estudos, projetos, aquisição de equipamentos e prestação de serviços para órgãos públicos, muitas vezes não promovem a compensação ao impacto causado ao meio ambiente.

Empreendimentos de alta complexidade, por exemplo: hidrelétricas, e o reconhecimento de impactos positivos são os principais enfoques considerados pelos trabalhos acadêmicos publicados nos primeiros vinte primeiros anos da exigência da avaliação de impactos ambientais (Duarte et al., 2017). Um maior aproveitamento de profissionais de diferentes campos da ciência poderia auxiliar na previsão de impactos (Almeida et al., 2017). Ainda assim observa-se uma evolução dos mecanismos de controle desse instrumento, uma vez que a desconsideração das propriedades cumulativas e sinérgicas dos impactos ambientais não afetam de maneira determinante a análise dos EIAs (Almeida et al., 2017).

\section{Licenciamento e a revisão de atividades efetiva ou potencialmente poluidoras}

A Lei Complementar $n^{\circ}$ 140/2011 definiu o licenciamento ambiental com um procedimento administrativo destinado a licenciar atividades ou empreendimentos utilizadores de recursos ambientais, efetiva ou potencialmente poluidores ou capazes, sob qualquer forma, de causar degradação ambiental (Brasil, 2011). Conforme consta na Lei supracitada, a localização, construção, instalação, ampliação, modificação e operação de empreendimentos e atividades utilizadoras de recursos ambientais que são potencialmente poluidoras ou podem causar degradação ambiental dependerão de licenciamento do órgão ambiental competente.

A Resolução CONAMA 237/1997 apresentou um rol de atividades ou empreendimentos sujeitos ao licenciamento ambiental, como a extração e tratamento de minerais, a indústria de madeira, a indústria química e atividades agropecuárias. A resolução ainda estabeleceu distinções para as diferentes etapas de execução de empreendimento, estabelecendo as licenças prévia, de instalação e operação (MMA, 1997). Como definido na Resolução CONAMA 237/1997, a licença prévia é concedida na fase inicial e autoriza a localização e concepção do empreendimento, a licença de instalação autoriza a instalação do empreendimento, e a licença de operação autoriza a operação da atividade ou empreendimento. 
Ao longo de 40 anos do PNMA, o licenciamento ambiental tornou-se o seu principal instrumento, e estabeleceu a ligação entre empreendedores e órgãos ambientais. A trajetória é marcada pela morosidade dos órgãos ambientais ao analisar os processos e omissão de informações relevantes por parte dos proprietários. A Lei n ${ }^{\circ}$ 140/2011 regulamentou a competência comum da União, Estados, Distrito Federal e Municípios na proteção ambiental, assim como buscou maior celeridade na emissão de licenças (Brasil, 2011).

Apesar da regulamentação, a capacidade técnica para analisar processos de licenciamento de maior complexidade nos estados e municípios é frágil, devido às divergências políticas, falta de modernização e baixa capacidade institucional, que também dificultam ações de descentralização (Chagas \& Vasconcelos, 2019; Nascimento et al., 2020). Mesmo em estados com maior número de empreendimentos passíveis de licenciamento ambiental, como Minas Gerais, São Paulo e Rio de Janeiro, a capacidade técnica de processar os pedidos de licença é desigual de acordo com a região de cada estado, principalmente em municípios menores (Nascimento \& Fonseca, 2017; Da Silva \& Borges, 2020).

São muitas as críticas sobre o licenciamento ambiental. É demasiado o tempo para a aquisição das licenças, o que acarreta em atrasos frequentes em obras. Destaca-se também a pouca efetividade das atividades de fiscalização dos empreendimentos. Esses fatores são decorrentes da pouca disponibilidade de profissionais e desmonte dos órgãos ambientais estaduais e federais, que apresentam corpo técnico defasado diante dos elevados períodos sem concurso público para preenchimento da vacância de profissionais gerada ao longo do tempo.

Diante dos gargalos no licenciamento ambiental, existem propostas de emenda à constituição que buscam maior celeridade neste processo. A PEC 65/2012 tramitou no Senado e propôs que o estudo prévio de impacto ambiental importasse autorização para a execução das obras, mas felizmente a proposta não avançou. Tramita, porém, na Câmara dos Deputados, a Proposta de Lei n 3.729/2004 (Câmara dos Deputados, 2020), que cria a Lei Geral de Licenciamento Ambiental. O texto tramitava há dezesseis anos e foi aprovado na Câmara dos Deputados, agora aguarda apreciação pelo Senado Federal. Empresários criticam a regulamentação excessiva do licenciamento, assim como a frente parlamentear ambientalista destaca que aprovar uma nova lei não vai resolver a questão do licenciamento ambiental no Brasil, já que os maiores problemas não estão na legislação, e sim na estrutura precária dos estados para analisar grande número de processos (Câmara dos Deputados, 2020).

É importante destacar que apressar as autorizações das licenças em nada garantirá o sistema de segurança dos grandes empreendimentos ou o amortecimento/mitigação/compensação dos impactos negativos, tanto para o meio ambiente quanto para a comunidade circunvizinha (Lima et al., 2019). As reformas do licenciamento ambiental devem ser fundamentadas em evidências obtidas com pesquisas científicas executadas por instituições idôneas, assim como devem alcançar os que estão à frente das mudanças dos regulamentos e procedimentos de licenciamento ambiental e AIA (Fonseca et al., 2017).

\section{Incentivos à produção e instalação de equipamentos e a criação ou absorção de tecnologia, voltados para a melhoria da qualidade ambiental}

O instrumento buscou incentivar a adoção de tecnologias mais limpas e apropriadas no processo produtivo, prevenindo a poluição e a degradação ambiental (De Moura, 2016). Destacam-se iniciativas governamentais instituídas na década de 1980, como o Programa de Controle da Poluição do Ar por Veículos Automotores (PROCONVE) e o Programa Nacional de Conservação de Energia Elétrica (PROCEL).

O PROCONVE está previsto na Resolução CONAMA 18/1986 e tem como objetivos: reduzir os níveis de emissão de poluentes por veículos automotores, executar inspeção veicular, conscientizar a sociedade e propor a melhoria dos combustíveis líquidos. O PROCEL foi instituído pela Portaria Interministerial 1.877/1985, do Ministério de Minas e Energia, e executado pela Eletrobrás. O programa buscou aumentar a eficiência dos bens e serviços, além de desenvolver hábitos e 
conhecimentos sobre o consumo eficiente de energia. Em 1993 foi lançado o Selo PROCEL, para identificar a eficiência em termos de energia elétrica dos equipamentos.

As Compras Públicas Sustentáveis (CPS) foram incorporadas ao processo licitatório para promover o desenvolvimento nacional sustentável mediante a inserção de critérios sociais, ambientais e econômicos nas aquisições de bens, contratações de serviços e execução de obras (MMA, 2020 a). De Oliveira \& Santos (2015) destacam que os estados de São Paulo, Santa Catarina, Rio Grande do Sul e Paraná alteraram dispositivos legais para se adequarem às CPS. No entanto, os autores concluíram que os estados contribuem de forma incipiente para o desenvolvimento sustentável, com destaque razoável para São Paulo.

A Avaliação Ambiental Estratégica (AAE) consiste em formas de avaliação de impacto e ações mais amplas que auxiliam na integração ambiental e na possibilidade de riscos em projetos mais abrangentes (Sánchez, 2017). Tipicamente, a AAE refere-se à avaliação das consequências ambientais de Políticas, Planos e/ou Programas (PPP), em geral no âmbito de iniciativas governamentais, embora possa ser aplicada em organizações privadas (Sánchez, 2017). O Brasil ainda não possui regulamentação de ordem federal específica a respeito dessa iniciativa, e a AAE foi objeto de projetos de lei entre 1988 e 2013 (Garcia \& Souza, 2015).

\section{Criação de espaços territoriais especialmente protegidos pelo Poder Público federal, estadual e municipal, tais como áreas de proteção ambiental, de relevante interesse ecológico e reservas extrativistas}

A criação de espaços territoriais especialmente protegidos teve sua redação editada pela Lei $n^{\circ} 7.804 / 1989$. O instrumento trata das áreas cuja finalidade é a proteção dos recursos ambientais, e para essa finalidade apresentam restrição em sua utilização (Brasil, 1989). Da Silva (2019) definiu os espaços territoriais especialmente protegidos como áreas públicas ou privadas que apresentam características ambientais que resultam em uma imodificabilidade relativa para uma utilização sustentável. Para o autor, as áreas visam à proteção da diversidade dos ecossistemas e do processo evolutivo das espécies, bem como a proteção e preservação dos recursos naturais e dos serviços ecossistêmicos.

Existem divergências sobre quais seriam os espaços territoriais especialmente protegidos. Com base na definição de Da Silva (2019), que abrange propriedades públicas e privadas, adota-se as Unidades de Conservação (UCs), previstas pelo Sistema Nacional de Unidades de Conservação da Natureza (SNUC) - Lei ${ }^{\circ}$ 9.985/2000; e as Áreas de Preservação Permanente (APP) e Reserva Legal (RL), ambas previstas pelo Código Florestal de 1965 e 2012, respectivamente, Lei ${ }^{\circ}$ 4.771/1965 e Lei nº 12.651/2012. Considerando que o Código Florestal de 1965 é anterior à PNMA, e que a APP e RL estavam presentes na Lei $\mathrm{n}^{\circ} 4.771 / 1965$, essas áreas devem ser consideradas como espaços territoriais especialmente protegidos, mesmo não tendo sido criadas com essa finalidade (Pereira \& Scardua, 2008).

De acordo com o inciso I, art. $2^{\circ}$, da Lei n ${ }^{\circ} 9.985 / 2000$, as UCs são definidas como o espaço territorial e seus recursos ambientais, que possuem características naturais relevantes, legalmente instituídos pelo Poder Público, com objetivos de conservação e limites definidos, sob regime especial de administração, e possuem garantias adequadas de proteção (Brasil, 2000). Existem 2.468 UCs no Brasil, totalizando 1.588.989,67 km² de áreas protegidas em área continental, concentradas, principalmente, na região Norte do Brasil (MMA, 2020 b).

As primeiras UCs do Brasil datam da década de 1930, período em que foram criadas importantes áreas, como o Parque Nacional da Serra dos Órgãos e o Parque Nacional do Iguaçu. No período anterior à aprovação da Lei n $7.804 / 1989$, foram criadas 297 unidades de conservação. Após a aprovação da referida Lei, foram criadas 2.171 UCs. Dentre elas, estão o Parque Nacional de Jericoacoara, muito frequentado por turistas, e o Parque Nacional Montanhas do Tumucumaque, maior parque nacional do Brasil. 
As UCs apresentam fiscalização e monitoramento deficientes, além de escassez de recursos do setor público (Muniz \& Pinheiro, 2019). Nesse contexto, é recorrente a ocorrência de atividades degradadoras como desmatamento, mineração ilegal e incêndios florestais em terras públicas. Tendo como base maio de 2019, foram identificados $797 \mathrm{~km}^{2}$ de desmatamento na Amazônia Legal, dos quais aproximadamente 271 km² ocorreram em UCs (Fonseca et al., 2019).

De acordo com a Lei ${ }^{\circ} 12.651 / 2012$, as APPs são áreas protegidas com função ambiental de preservar os cursos d'água e o solo, bem como assegurar o bem-estar das populações humanas, e a RL consiste em uma fração da propriedade rural com a função de assegurar o uso econômico de modo sustentável dos recursos naturais do imóvel rural, auxiliar a conservação e a reabilitação dos processos ecológicos e promover a conservação da biodiversidade, bem como o abrigo e a proteção de fauna silvestre e da flora nativa (Brasil, 2012). Por meio do ato declaratório informático Cadastro Ambiental Rural (CAR), também previsto na Lei ${ }^{\circ}$ 12.651/2012, as propriedades rurais apresentam 21.687.978,21 ha de APP e 135.194.100,53 ha de RL, com cerca de 12,9 e 108,2 milhões de ha de remanescentes de vegetação nativa, respectivamente (SFB, 2020).

A extensa área com ausência de remanescentes de vegetação nativa é um indicativo do passivo ambiental apresentado pelas propriedades rurais. Apenas para o bioma Cerrado, Guidotti et al. (2017) afirmam que o passivo ambiental é de aproximadamente 6 milhões de ha, sendo 1,9 milhão de ha de APP e 4,2 milhões de ha de RL.

A legislação ambiental brasileira mostra-se eficiente na criação de áreas prioritárias que devem ser protegidas, seja em propriedades privadas ou em áreas públicas. Ao observar a grande quantidade de UCs com áreas degradadas e vastas áreas de APP e RL sem remanescentes de vegetação nativa, fica evidente que há uma fragilidade no processo de fiscalização, resultando no não cumprimento dos dispositivos legais. Os mecanismos utilizados para coibir atividades predatórias nas áreas protegidas são políticas de comando e controle, que não são eficazes a ponto de inibir a alteração do uso do solo em APPs e RL e a atividade ilegal em unidades de conservação.

\section{Sistema nacional de informações sobre o meio ambiente}

O Sistema Nacional de Informações sobre o Meio Ambiente (SINIMA) é o instrumento da PNMA encarregado de organizar, integrar e compartilhar informações ambientais, de modo que elas sejam disponibilizadas no âmbito do Sistema Nacional do Meio Ambiente (SISNAMA). Assim, o SINIMA é um instrumento do SISNAMA que tem por objetivo produzir dados e informações sobre o meio ambiente na esfera Federal (MMA, 2004).

A administração do SINIMA é de responsabilidade do Ministério do Meio Ambiente (MMA), com suporte do Comitê gestor criado pela Portaria MMA 310/2004. O comitê é composto pelo MMA, Instituto Brasileiro do Meio Ambiente e Recursos Naturais Renováveis (IBAMA), ANA, Instituto de Pesquisas Jardim Botânico do Rio de Janeiro, Fórum Brasileiro de Organizações Não-Governamentais para o Meio Ambiente e o Desenvolvimento Sustentável (FBONS), Associação Brasileira Entidades Ambientais (ABEMA) e Associação Nacional de Órgãos Municipais do Meio Ambiente (ANAMMA) (MMA, 2004).

Sobre o arcabouço legal, destaca-se a Lei ${ }^{\circ} 10.650 / 2003$, que aborda o acesso público aos dados e informações dos órgãos e entidades vinculados ao SISNAMA, e determina a obrigatoriedade na disponibilização de dados ambientais (Brasil, 2003). No âmbito do SINIMA, a Portaria MMA 365/2015 estabeleceu o Programa de Monitoramento Ambiental dos Biomas Brasileiros (MMA, 2015) e o Código Florestal (Lei n ${ }^{\circ}$ 12.651/2012) criou o Cadastro Ambiental Rural (CAR) (Brasil, 2012), que posteriormente foi detalhado por meio da Instrução Normativa MMA 2/2014 (MMA, 2014). O CAR é o instrumento mais importante do SINIMA, e consiste no registro eletrônico exigido para todos os imóveis rurais com a finalidade de integrar as informações ambientais, e assim construir uma base de dados para controle, monitoramento, planejamento ambiental e econômico, e combate ao desmatamento. 
O CAR é considerado um sistema menos burocrático do que as declarações realizadas em cartório (Laudares et al., 2014), e foram cadastradas 6,5 milhões de imóveis rurais até janeiro de 2020 (SFB, 2020). Por outro lado, o CAR apresenta uma fragilidade para o levantamento geométrico (De Oliveira \& Oliveira, 2019), e a natureza declaratória dos dados pode gerar uma baixa confiabilidade (Tupiassu et al., 2017).

Outro ponto de crítica do sistema é o fato de que o SINIMA demorou muitos anos para iniciar seu funcionamento, que ocorreu apenas em 2006, 25 anos depois da aprovação da lei (Silva, 2012). Por fim, não há um sistema de informação ambientais unificado capaz de comportar informações de diferentes bases de dados, o que resulta em um sistema de informações fragmentado. Para Silva (2012), o SINIMA não é estruturado para receber as informações das diferentes bases de dados, e a falta de dados caracteriza o desconhecimento sobre a utilização dos serviços, e se eles atendem às demandas.

\section{Cadastro Técnico Federal de Atividades e Instrumentos de Defesa Ambiental}

O Cadastro Técnico Federal (CTF) teve como objetivo identificar pessoas físicas e jurídicas sob controle ambiental e fiscalização ambiental, conforme previsto em legislação federal, gerando informações para a gestão ambiental no Brasil (IBAMA, 2020). Nos processos de licenciamento e autorizações para intervenção ambiental do IBAMA, o CTF é o primeiro procedimento executado pelo empreendedor nos processos de licenciamento ambiental, intervenção florestal integrados e solicitação de outorga de direito de uso de recursos hídricos não integrados.

O CTF se divide em duas modalidades: Cadastro Técnico Federal de Atividades Potencialmente Poluidoras e/ou Utilizadoras de Recursos Ambientais (CTF/APP) e Cadastro Técnico Federal de Atividades e Instrumentos de Defesa Ambiental - CTF/AIDA. O CTF/AIDA é o registro obrigatório de pessoas físicas ou jurídicas que se dedicam à consultoria técnica sobre problemas ecológicos e ambientais e a indústria e comércio de equipamentos, aparelhos e instrumentos destinados ao controle de atividades efetiva ou potencialmente poluidoras (IBAMA, 2013). Nesse contexto, o profissional que deseja elaborar projeto de EIA/RIMA para apreciação do IBAMA deverá preencher o cadastro.

O CTF/AIDA foi normatizado pela Resolução CONAMA 1/1988, e detalhado em 2013 com a publicação da Instrução Normativa IBAMA 10/2013 (IBAMA, 2013). O CTF/AIDA tem sua importância evidenciada pelo CONAMA, impedindo a elaboração de estudos ambientais por profissionais que não possuem atribuição técnica para determinadas atividades. O cadastro é uma ferramenta importante, com potencial de definir políticas públicas tanto no âmbito da defesa ambiental quanto do reconhecimento de regiões com aptidão para o desenvolvimento, baseando-se nas especificidades locais e na exploração de recursos (Barros et al., 2012).

Os profissionais vinculados aos estudos passam a ser responsáveis por possíveis infrações cometidas pela empresa contratante e estão sujeitos à aplicação do regime ético-disciplinar a que se subordinam os profissionais vinculados ao Conselho Federal de Engenharia e Agronomia (CONFEA) e ao Conselho Federal de Biologia (CFBIO). Essas entidades agrupam parcela dos profissionais normalmente envolvidos na avaliação de impactos e elaboração de estudos ambientais para a instalação e operação de obras e atividades efetiva ou potencialmente causadoras de degradação (Barbosa, 2017).

A conduta ética dos profissionais habilitados e vinculados aos conselhos de classe para atuação nos projetos de empreendimentos também estão sujeitos ao controle ambiental dos órgãos do SISNAMA. O regime ético-disciplinar pode não significar limite administrativo para aplicação de penalidades aos profissionais transgressores da ordem ambiental vigente. Assim, a finalidade do processo ético visa resguardar a dignidade da profissão em detrimento de práticas antiéticas ou ilegais, mostrando-se relevante averiguar a responsabilidade em outras esferas legalmente estabelecidas (Iasbik \& Gomes, 2018). 


\section{Penalidades disciplinares ou compensatórias ao não cumprimento das medidas necessárias à preservação ou correção da degradação ambiental}

O instrumento foi regulamentado pela Lei $\mathrm{n}^{\circ}$ 9.605/1998, com previsibilidade para estabelecer sanções penais e administrativas em função de conduta lesiva ao meio ambiente (Brasil, 1998). No âmbito administrativo, o dispositivo legal definiu como infração administrativa ambiental toda ação ou omissão que viole as regras jurídicas de uso, gozo, promoção, proteção e recuperação do meio ambiente. Foram definidas também as sanções administrativas, que preveem a possibilidade de multas impostas por Estados, Municípios, Distrito Federal ou Territórios substituírem as multas federais que possuem a mesma incidência.

O Decreto $n^{\circ}$ 6.514/2008 (Brasil, 2008) detalhou os dispositivos de infração administrativa previstos na Lei $n^{\circ}$ 9.605/1998. O decreto dispôs sobre as infrações e sanções administrativas ao meio ambiente, estabeleceu o processo administrativo federal para apuração das infrações. Assim, o decreto objetivou dar maior celeridade à cobrança das multas. Sirvinskas (2018) destaca que, no decreto anterior, o infrator poderia recorrer utilizando-se de quatro instâncias, enquanto o decreto vigente permite apenas duas, buscando tornar mais célere o procedimento.

Mesmo com iniciativas que buscaram a celeridade na aplicação de infrações administrativas ambientais, persiste a dificuldade da aplicação do instrumento de penalidade, bem como a fiscalização de órgãos ambientais competentes. A fragilidade na aplicação de sanções é constatada tanto em medidas de compensação ambiental previstas para empreendimentos potencialmente poluidores quanto para proteção dos biomas (Melo et al., 2011; Gomes, 2019).

\section{Relatório de Qualidade do Meio Ambiente}

O Relatório de Qualidade do Meio Ambiente (RQMA) é um documento de publicação periódica que visa apresentar o panorama da qualidade ambiental no Brasil (IBAMA, 2013). O documento sintetiza, sistematiza e analisa informações ambientais para a gestão dos recursos naturais e conservação dos ecossistemas no país. O público alvo são os gestores de meio ambiente federais, estaduais e municipais, atores privados de educação e pesquisa, organismos internacionais, organizações não governamentais, meios de comunicação e público em geral (IBAMA, 2013).

Em 2013, o RQMA apresentou sete capítulos abordando temas como atmosfera, água, terra, biodiversidade, florestas, ambiente costeiro e marinho e ambiente urbano. O relatório possui a colaboração de mais de 50 (cinquenta) instituições associadas ao meio ambiente, além de instituições de ensino superior. A metodologia utilizada para elaboração do RQMA 2013 baseou-se no modelo DPSIR (Driving Forces, Pression, State, Impact, Response), traduzido como força-motriz, pressão, estado, impacto, resposta.

Para Sirvinskas (2018), o RQMA é um importante instrumento para a análise da efetividade das políticas públicas aplicadas na esfera federal. Segundo o autor, com base nas informações disponibilizadas no relatório, o poder público pode manter ou alterar políticas para atender às necessidades ecológicas nas diversas esferas administrativas. No entanto, desde 2013 não houve a publicação de um novo relatório. Eventos recentes, como as queimadas na Amazônia e Pantanal, a incorporação de áreas nativas ao processo de expansão da agropecuária, a periodicidade das chuvas e qualidade do ambiente urbano são fatores que adicionariam novos dados a um novo RQMA.

\section{Garantia da prestação de informações relativas ao Meio Ambiente}

$\mathrm{O}$ instrumento possui conformidade com o direito de que todo cidadão possui de receber informações do poder público, previsto na Constituição Federal, no art. $5^{\circ}$ incisos XIV e XXXIII. Por meio dele, a PNMA buscou centralizar e sistematizar informações relevantes relacionadas aos processos de decisões em todos os níveis de poder (Sirvinskas, 2018). 
A Lei $n^{\circ}$ 10.650/2003 dispôs sobre o acesso público aos dados e informações existentes nos órgãos e entidades integrantes do SISNAMA (Brasil, 2003). Assim, informações relativas à qualidade do meio ambiente, monitoramento e emergências ambientais, emissões de efluentes, substâncias tóxicas, diversidade biológica e organismos geneticamente modificados passaram a ser divulgadas em meio escrito, visual, sonoro e eletrônico. O dispositivo é condizente às Resoluções CONAMA 06/1986 e 379/2006 que, respectivamente, tratam da publicação de pedidos de licenciamento em diário oficial (MMA, 1986) e regulamentação do sistema de dados e informações sobre a gestão florestal no âmbito do SISNAMA (MMA, 2006).

A informação ambiental se faz imprescindível, pois não há como se prevenir de uma atividade de risco caso não se saiba no que ela consiste, e não há como pedir a reparação de um dano causado por atividade sem saber o responsável por ela (Paiano \& Maito, 2016). A divulgação abrangente de ações de responsabilidade ambiental é negligenciada mesmo em empresas de alto impacto ambiental (Freitas et al., 2018), e a falta de sensibilidade por parte das empresas prejudica o meio ambiente e a população em geral.

\section{Cadastro Técnico Federal de atividades potencialmente poluidoras}

O CTF/APP, mencionado anteriormente no instrumento de no VIII, é um registro obrigatório para pessoas físicas ou jurídicas que se dedicam a atividades potencialmente poluidoras e/ou extração, produção, transporte e comercialização de produtos potencialmente perigosos ao meio ambiente, e produtos e subprodutos da fauna e flora. O CTF/APP foi regulamentado pela Instrução Normativa IBAMA 6/2013, que apresenta 22 (vinte e duas) categorias de atividades que exigem o preenchimento do cadastro (Brasil, 2013). Mais recente, a Instrução Normativa IBAMA no 12/2018 instituiu as Fichas Técnicas de Enquadramento (FTEs), utilizadas para verificar a obrigação de inscrição no CTF/APP (BRASIL, 2018). As FTEs são guias para a identificação de atividade a ser declarada nos formulários de inscrição ou de alteração no CTF/APP.

Por meio do acesso à plataforma disponibilizada no site do IBAMA, e devido à quantidade de informações disponibilizadas, pode-se afirmar que a CTF é um instrumento muito utilizado da PNMA. A página do cadastro apresenta o painel de informações do CTF/APP que, ao utilizar filtros, mostra a quantidade de cadastros por região, estado e município, bem como as principais categorias de atividade.

Até meados de 2020, os dados indicaram que a região sudeste, especialmente o estado e município de São Paulo, apresenta a maior quantidade de empresas cadastradas. O comércio de combustíveis e derivados de petróleo é a atividade com maior número de CTF/APP. No entanto, as atividades não relacionadas na Instrução Normativa IBAMA 6/2013 correspondem a categoria com o maior número de empresas cadastradas (Brasil, 2013). Dessa maneira, é possível constatar uma defasagem na inserção de novas atividades potencialmente poluidoras no ordenamento jurídico ambiental.

\section{Instrumentos econômicos, como concessão florestal, servidão ambiental, seguro ambiental e outros}

Instrumentos econômicos previstos no ordenamento jurídico ambiental da PNMA configuram-se uma proposta de estímulo do agente econômico, que poderá optar voluntariamente em aderir, visando um ganho econômico direto (Derani \& Souza, 2013). O principal gargalo na execução desse instrumento ocorre na monetarização de serviços ambientais (Schimaleski \& Garcias, 2020).

A concessão florestal e a servidão florestal/ambiental são as principais modalidades de ganho financeiro para os agentes que optam em preservar a biota. A concessão florestal está prevista na Lei $\mathrm{n}^{\circ} 11.284 / 2006$, sendo definida como a “delegação onerosa, feita pelo poder concedente, do direito de praticar manejo florestal sustentável para exploração de produtos e serviços numa unidade de manejo (Brasil, 2006), mediante licitação, à pessoa jurídica, em consórcio ou não, que 
atenda às exigências do respectivo edital de licitação e demonstre capacidade para seu desempenho, por sua conta e risco e por prazo determinado".

A lei destacou que a concessão terá como objetivo a exploração de produtos e serviços florestais, contratualmente especificados, em unidade de manejo de floresta pública, com perímetro georreferenciado, registrada no respectivo cadastro de florestas públicas e incluída no lote de concessão florestal. Sirvinskas (2018) afirma que a concessão de uso de bem público para exploração recursos florestais será autorizada por ato do poder concedente, mediante a realização de processo licitatório tal qual exige a Lei $n^{\circ}$ 8.666/1993, que dispõe sobre as normas gerais sobre licitações e contratos administrativos (Brasil, 1993).

A gestão de concessões florestais é de responsabilidade do Serviço Florestal Brasileiro (SFB), sob a coordenação do MMA até 2018, e vinculado ao Ministério da Agricultura Pecuária e Abastecimento (MAPA) a partir de 2019. Estudos técnicos e consulta pública são realizadas antes da publicação do edital de licitação, e o SFB divulga anualmente, por meio do Plano Anual de Outorga Florestal (PAOF), as florestas públicas passíveis de serem concedidas. As empresas interessadas devem possuir documentação adequada e estarem cientes das exigências ambientais brasileiras, bem como não deverão possuir condenação por crimes ambientais, tributários e previdenciários. A empresa ganhadora será aquela que apresentar a melhor proposta de preço pela exploração madeireira, devendo cumprir as exigências sociais e ambientais.

As áreas em exploração devem ser monitoradas com o intuito de descrever os padrões de regeneração e crescimento das espécies para garantir o abastecimento futuro de madeira (Jacobsen et al., 2020). Na região amazônica, onde estão as florestas concedidas para manejo florestal, o desafio está em promover inclusão social, mecanismos de resolução de conflitos, gestão pós-contrato e competição com a madeira ilegal (Lima \& Azevedo-Ramos, 2020).

A servidão florestal foi instituída pela Medida Provisória 2.166-67/2001, que alterou o antigo Código Florestal (Lei n ${ }^{\circ}$ 4.771/1965) e passou a permitir que o proprietário de imóvel rural destine parte da terra para a criação de área de proteção ambiental, além da reserva legal. A servidão ambiental foi criada por meio da Lei ${ }^{\circ}{ }^{\circ} 11.284 / 2006$, na qual prevê que proprietário renuncie, em caráter permanente ou temporário, total ou parcialmente, ao direito de uso, exploração ou supressão de recursos naturais existentes na propriedade (Brasil, 2006).

O novo código florestal, Lei $\mathrm{n}^{\circ}$ 12.651/2012, previu a servidão ambiental e descreveu algumas exigências a serem cumpridas por parte do proprietário, como o memorial descritivo da área, o objeto da servidão, direitos e deveres do proprietário e o período em que a área permanecerá sob o regime. O instrumento de servidão possibilita ao proprietário uma exploração "econômico/ecológica" de sua propriedade, maior efetividade à tarefa de proteção dos órgãos ambientais e alicerça a atividade do empreendedor com recursos e ferramentas de cumprimento das obrigações ecológicas (Gomes, 2018).

Um dos maiores gargalos do instrumento de servidão ambiental/florestal é a valoração monetária. Assim, deve haver sintonia entre economistas, ecólogos, biólogos e demais pesquisadores. O diálogo construtivo e aberto entre esses profissionais é essencial para a construção de uma massa crítica sólida para se desvendar os nexos entre ecossistemas, sistema econômico e bem-estar humano (Andrade \& Romeiro, 2013).

\section{Considerações Finais}

O Brasil possui uma legislação ambiental consistente, mas que enfrenta dificuldades na implantação e cumprimento das leis. Foram observados longos períodos para a implementação dos instrumentos previstos na PNMA, bem como a desatualização da legislação diante das modificações ocorridas nos setores produtivo, ambiental e tecnológico desde a aprovação da lei.

Os setores ambientais competentes não trabalham de forma sincronizada, o que dificulta o bom funcionamento dos instrumentos. Soma-se também o baixo nível de fiscalização e corpo profissional pouco capacitado para a execução das 
atividades. Diante da existência de uma legislação, o Estado deve garantir o seu cumprimento. Isso se dá por meio da contratação de funcionários capacitados para o desempenho das atividades e do processo de fiscalização eficiente, em que as penalidades por infrações sejam de fato cumpridas.

\section{Referências}

Almeida, A. N., Kanieski, M. R., Soares, R. C. \& Angelo, H. (2017). Principais problemas na previsão e avaliação de impactos ambientais nos Estudos de Impacto Ambiental (EIAs): uma aplicação da análise de correlação canônica. Revista Brasileira de Gestão Ambiental e Sustentabilidade, 4(7), 31-42.

Andrade, D. C. \& Romeiro, A. R. (2013). Valoração de serviços ecossistêmicos: por que e como avançar? Sustentabilidade em Debate, 4(1), 43-58.

Antunes, P. B. (2010). Direito ambiental. (12a ed.), Lumen Juris.

Barbosa, D. R. (2017). Os instrumentos da política nacional de meio ambiente: versatilizando o aprendizado sob a ótica do estudo de educação à distância. Khóra: Revista Transdiciplinar, 4(5): 1-14.

Barros, D. A., Borges, L. A. C., Nascimento, G. O., Pereira, J. A. A., Rezende, J. L. P., Silva, R. A. (2012). Breve análise dos instrumentos da política de gestão ambiental brasileira. Política \& Sociedade, 11(22), 155-179.

Brasil. Constituição da República Federativa do Brasil, de outubro de 1988. http://www.planalto.gov.br/ccivil_03/constituicao/constituicao.htm.

Brasil. (2002). Decreto $n^{\circ} 4.297$ de 10 de julho de 2002. http://www.planalto.gov.br/Ccivil_03/decreto/2002/D4297.htm.

Brasil. (2013). Instrução normativa n 6 de março de 2013. https://www.gov.br/ibama/pt-br/centrais-de-conteudo/ibama-in-6-2013-compilada-in-11-2018-pdf.

Brasil. (2018). Instrução normativa $n^{o} 12$ de abril de 2018. http://www.ibama.gov.br/phocadownload/ctf/2018/Ibama-IN-12-2018.pdf.

Brasil. (1980). Lei $n^{o}$ 6.803, de julho de 1980. http://www.planalto.gov.br/ccivil_03/leis/16803.htm.

Brasil. (1981). Lei $n^{\circ}$ 6.938, de agosto de 1981. http://www.planalto.gov.br/ccivil_03/leis/16938.htm.

Brasil. (1989). Lei $n^{\circ}$ 7.804, de julho de 1989. Altera a Lei $n^{\circ} 6.938$, de 31 de agosto de 1981, que dispõe sobre a Política Nacional do Meio Ambiente, seus fins e mecanismos de formulação e aplicação, a Lei $n^{\circ} 7.735$, de 22 de fevereiro de 1989, a Lei $n^{\circ}$ 6.803, de 2 de julho de 1980, e dá outras providências. http://www.planalto.gov.br/ccivil_03/leis/17804.htm.

Brasil. (2000). Lei $n^{\circ}$ 9.985, de julho de 2000. http://www.planalto.gov.br/ccivil_03/leis/19985.htm.

Brasil. (1993). Lei $n^{\circ}$ 8.666, de julho de 1993. http://www.planalto.gov.br/ccivil_03/leis/18666cons.htm.

Brasil. (2003). Lei $n^{\circ}$ 10650, de abril de 2003. http://www.planalto.gov.br/ccivil_03/leis/2003/110.650.htm.

Brasil. (2006). Lei $n^{\circ}$ 11284, de março de 2006. http://www.planalto.gov.br/ccivil_03/_ato2004-2006/2006/lei/111284.htm.

Brasil. (2011). Lei Complementar no 140 de 8 de dezembro de 2011. http://www.planalto.gov.br/ccivil_03/leis/lcp/lcp140.htm.

Brasil. (2012). Lei n 12.651, de maio de 2012. http://www.planalto.gov.br/ccivil_03/_Ato2011-2014/2012/Lei/L12651.htm.

Câmara dos Deputados.(2020). Deputados defendem aprovação de novas leis para licenciamento ambiental e pagamento por serviços ambientais. https://www.camara.leg.br/noticias/683539-deputados-defendem-aprovacao-de-novas-leis-para-licenciamento-ambiental-e-pagamento-por-servicosambientais/.

Chagas, M. \& Vasconcelos, E. (2019) .Licenciamento ambiental e desenvolvimento sustentável: possíveis integrações para territórios singulares na Amazônia brasileira. Journal of Geography and Spatial Planning, 17, 5-28.

Comissão de Brundtland (1991). Comissão Mundial sobre Meio Ambiente e Desenvolvimento, o nosso futuro comum. (2a ed.), Fundação Getúlio Vargas.

Da Silva, J. A. (2019). Direito ambiental constitucional. (11a ed.), Malheiros.

Da Silva, A. F \& Vieira, C. A. (2017). Aspectos da poluição atmosférica: uma reflexão sobre a qualidade do ar nas cidades brasileiras. Ciência $e$ Sustentabilidade, 3(1), 166-189.

Da Silva, M. L. M. \& Borges, L. A. C. (2020). Descentralização do licenciamento ambiental em Minas Gerais. Periódico Eletrônico “Fórum Ambiental da Alta Paulista", Tupã, 16(2), 99-113.

De Moura, A. M. M. (2016). Aplicação dos instrumentos de política ambiental no brasil: avanços e desafios. In: De Moura AMM (Org). Governaça Ambiental no Brasil: instituições, atores e politícas publicas. Ipea. p.111-145.

De Oliveira, B. C. S. C. M. \& Dos Santos, L. M. L. (2015). Compras públicas como política para o desenvolvimento sustentável. Revista de Administracão Pública, 49(1), 189-206.

De Oliveira, L. \& Oliveira, F. H. (2019). Verificação da integração entre o Cadastro Ambiental Rural (CAR) e o Cadastro Nacional de Imóveis Rurais (CNIR) sob a ótica do cadastro territorial multifinalitário. Geosul, 34(70): 339-357. 
Derani, C. \& Souza K. S. (2013). Instrumentos econômicos na política nacional do meio ambiente: por uma economia ecológica. Veredas do Direito, 10(19): 247-272.

Duarte, C. G., Dibo, A. P. A., Sánchez, L. E. (2017). O que diz a pesquisa acadêmica sobre Avaliação de Impacto e Licenciamento Ambiental no Brasil? Ambiente \& Sociedade, 20(1), 245-278.

Fonseca, A. J. M., Cardoso, D., Ribeiro, J., Salomão, R., Souza, C. J., \& Veríssimo, A. (2019). Boletim do desmatamento da Amazônia Legal (maio 2019). Imazon.

Fonseca, A., Montaño, M., \& Moretto, E. M. (2017). A importância do conhecimento científico para o aprimoramento do Licenciamento e da Avaliação de Impacto Ambiental no Brasil. Desenvolvimento e Meio Ambiente, 43, 1-5.

Freitas, M. R. O., Santos, S. M., \& Crisóstomo, V. L. (2018). Nível de abrangência da informação ambiental divulgada nos relatórios de sustentabilidade de empresas brasileiras com potencial de impacto ao meio ambiente. Revista Contabilidade e Controladoria, 10(3), 143-161.

Garcia, H. S., \& Souza, M. C. S. A. (2015). Avaliação ambiental estratégica: uma visão da construção ideológica mundial e os seus reflexos no Brasil. Revista da AJURIS, 42(139), 113-136.

Gomes, M. K. (2018). Servidão ambiental e os instrumentos econômicos no marco legal brasileiro environmental servitude and economic instruments in brazilian legal framework. Revista de direito desenvolvimento da UNICATÓLICA, 1(1), 84-98.

Gomes, M. K. (2019). Sanções ambientais por supressão irregular de vegetação do bioma Mata Atlântica. Revista Direito Ambiental e Sociedade, 9(2), 271298.

Guidotti, V., Freitas, F. L. M., Sparovek, G., Pinto, L. F. G., Hamamura, C., Carvalho, T., \& Cerignoni, F. (2017). Números detalhados do novo código florestal e suas implicações para os PRAs. Sustentabilidade em debate, 5, 1-9.

Iasbik, T. A. \& Gomes, M. F. (2018). A responsabilidade do profissional na defesa do meio ambiente. Revista Direito em Debate, 27(50), 27-37.

Instituto Brasileiro do Meio Ambiente e dos Recursos Naturais Renováveis (IBAMA). (2020). Cadastro Técnico Federal de Atividades Potencialmente Poluidoras elou Utilizadoras de Recursos Ambientais (CTF/APP), 02 de julho de 2020. https://www.gov.br/ibama/pt-br/assuntos/servicos/cadastros/cadastrotecnico-federal-ctf/cadastro-tecnico-federal-de-atividades-potencialmente-poluidoras-e-ou-utilizadoras-de-recursos-ambientais-ctf-app/cadastro-tecnicofederal-de-atividades-potencialmente-poluidoras-e-ou-utilizadoras-de-recursos-ambientais-ctf-app.

Instituto Brasileiro do Meio Ambiente e dos Recursos Naturais Renováveis (IBAMA). 2013. Instrução Normativa $n^{o} 10$, de 27 maio 2013 . Diário Oficial da União, Brasília, 28 maio 2013, seção 01, p. 62. https://www.gov.br/ibama/pt-br/assuntos/servicos/cadastros/cadastro-tecnico-federal-ctf/copy_of_cadastrotecnico-federal-de-atividades-e-instrumentos-de-defesa-ambiental-ctf-aida\#ctf/aidaeoresponsaveltecnicodosinaflor.

Instituto Brasileiro do Meio Ambiente e dos Recursos Naturais Renováveis (IBAMA). (2013). Relatório de Qualidade do Meio Ambiente (RQMA). Brasília: Ibama. http://www.ibama.gov.br/phocadownload/qualidadeambiental/relatorios/RQMA_2013.pdf.

Jacobsen, R. H. F., Sccoti, M. S. V., Fagundes, S. T. S., Brito Junior, J. F., \& Biazatti, S. C. (2020). Impacts on vegetation after selective cutting in forest concession area in the southwestern brazilian amazon. Floresta, 50(4), 1778-1787.

Laudares, S. S. A., Da Silva, K. G., \& Borges, L. A. C. (2014). Cadastro ambiental rural: uma análise da nova ferramenta para regularização ambiental no Brasil. Desenvolvimento e Meio Ambiente, 31, 111-122.

Lima. M. M., Castro, L. O. M., Pedrosa, C. M. (2019). Reflexionando sobre o licenciamento ambiental de barragens de rejeitos Minerais em Minas Gerais (Brasil). Revista Meio Ambiente e Sustentabilidade, 17(8), 126-136.

Lima, R. Y. M., Azevedo-Ramos, C. (2020). Compliance of Brazilian forest concession system with international guidelines for tropical forests. Forest Policy and Economics, 119, 102285.

Lopes, L. C. P. \& Ribeiro, J. C. J. (2016). O papel da avaliação de impacto ambiental para adoção de medidas compensatórias. Revista de Direito Ambiental e Socioambientalismo, 2(1), 148-169.

Melo, M. G. S, Silva, V. D., \& Sobral, M. C. M. (2011) Análise da aplicação das penalidades disciplinares e compensatórias por danos ambientais ao setor sucroalcooleiro de Pernambuco, Brasil. Revista Brasileira de Ciências Ambientais, 22: 50-59.

Ministério do Meio Ambiente (MMA). (2020a). Compras públicas sustentáveis. http://a3p.mma.gov.br/compras-publicas-sustentaveis/.

Ministério do Meio Ambiente (MMA) (2004). Portaria MMA n $n^{o}$ 310, de 13 de dezembro de 2004. https://www.normasbrasil.com.br/norma/portaria-3102004_187904.html.

Ministério do Meio Ambiente (MMA). (1986). Resolução CONAMA nº 01, de janeiro de 1986. http://www2.mma.gov.br/port/conama/res/res86/res0186.html..

Ministério do Meio Ambiente (MMA). (1986). Resolução CONAMA $n^{o}$ 06, de janeiro de 1986. http://www2.mma.gov.br/port/conama/legiabre.cfm?codlegi=29.

Ministério do Meio Ambiente (MMA). (1986). Resolução CONAMA $n^{o}$ 20, de junho de 1986. https://www.icmbio.gov.br/cepsul/images/stories/legislacao/Portaria/1986/res_conama_20_1986_revgd_classificacaoaguas_altrd_res_conama_274_2000_revg d_357_2005.pdf.

Ministério do Meio Ambiente (MMA). (1997). Resolução CONAMA $n^{\circ}$ 237, de 19 de dezembro de 1997. http://www2.mma.gov.br/port/conama/res/res97/res23797.html. 
Research, Society and Development, v. 11, n. 3, e15711326262, 2022

(CC BY 4.0) | ISSN 2525-3409 | DOI: http://dx.doi.org/10.33448/rsd-v11i3.26262

Ministério do Meio Ambiente (MMA). (2000). Resolução CONAMA $n^{o}$ 274, de novembro de 2000. http://www2.mma.gov.br/port/conama/legiabre.cfm?codlegi=272.

Ministério do Meio Ambiente (MMA). (2005). Resolução CONAMA $n^{o} \quad 357$ de março de 2005 . http://www2.mma.gov.br/port/conama/legiabre.cfm?codlegi=459.

Ministério do Meio Ambiente (MMA). (2006). Resolução CONAMA $n^{o} \quad 379$, de outubro de 2006 . http://www2.mma.gov.br/port/conama/legiabre.cfm?codlegi=511.

Ministério do Meio Ambiente (MMA) (2009). Resolução CONAMA $n^{o}$ 410, de maio de 2009 .

http://www2.mma.gov.br/port/conama/legiabre.cfm?codlegi=603.

Ministério do Meio Ambiente (MMA). (2011). Resolução CONAMA $n^{o}$ 430, de maio de 2011 http://www2.mma.gov.br/port/conama/legiabre.cfm?codlegi=646.

Ministério do Meio Ambiente (MMA). (2018). Resolução CONAMA $n^{\circ}$ 491, de novembro de 2018. http://www2.mma.gov.br/port/conama/legiabre.cfm?codlegi=740.

Ministério do Meio Ambiente (MMA). (2020). Painel Unidades de Conservação brasileiras em 2020. https://dados.gov.br/dataset/unidadesdeconservacao/resource/c0babb3e-ec4e-4db5-a2b6-b79477260b0f.

Morais, L. A. \& Freitas, L. S. (2020). Democracia e meio ambiente: um estudo bibliométrico da produção científica. Research, Society and Development, 9(7), $1-32$.

Pinheiro, A. S. \& Muniz, T. F. (2019). Concessão florestal como instrumento para a redução de exploração ilegal madeireira em Unidades de Conservação em Rondônia. Revista FAROL - Rolim de Moura, 8(8), 121-142.

Nascimento, T. \& Fonseca, A. (2017). A descentralização do licenciamento ambiental na percepção de partes interessadas de 84 municípios brasileiros. Desenvolvimento e Meio Ambiente, 43, 152-170.

Nascimento, T., Abreu, E. L., Fonseca, A. (2020). Decentralization of environmental licensing and impact assessment in Brazil: Literature and regulatory reviews. Ambiente e Sociedade, 23, 1-22.

Novo, B. N. (2017). O direito internacional ambiental. Revista Âmbito Jurídico $n^{\circ} 166$ - Ano XX - Nov./2017. https://ambitojuridico.com.br/edicoes/revista166/o-direito-internacional-ambiental/.

Paiano, D. B \& Maito, D. C. (2016) A contribuição da lei de acesso à informação para a ética ambiental como forma de concretização para a cidadania ambiental. Revista Nova Hileia, 1(1), 54-70.

Pereira, P. F \& Scardua, F. P. (2008). Espaços territoriais especialmente protegidos: conceito e implicações jurídicas. Ambiente \& Sociedade, 11(1), 81-97.

Rosa, F. S. (2018). Plano Diretor Ambiental como estratégia de desenvolvimento rural e urbano. Boletim Paulista de Geografia, 100, 96-111.

Sánchez, L. E. (2013). Avaliação de impacto ambiental - conceitos e métodos. (2a ed.), Oficina de Textos.

Sánchez, L. E. (2017). Por que não avança a avaliação ambiental estratégica no Brasil? Estudos Avançados, 31(89), 167-183.

Santiago, T. O. M, De Rezende, T. O. M, Santos, A. A., \& Borges, A. F. (2016). A eficácia do estabelecimento de padrões de qualidade ambiental. Revista Gestão \& Sustentabilidade Ambiental, 5(2), 85-111.

Schimaleski, A.P. C. \& Garcias, C. M. (2020). Reflexões sobre o potencial desconhecido do pagamento por serviços ambientais como instrumento para a gestão de mananciais hídricos urbanos. Cadernos Metrópole, 22(48): 601-616.

SFB (Serviço Florestal Brasileiro) (2020). Boletim informativo: Edição Especial - Janeiro 2020. http://www.florestal.gov.br/documentos/car/boletim-docar/4418-revisao-boletim-car-encaminhar-07abril2020-1/file..

Silva, M. S. (2012). Sistema nacional de informação sobre o meio ambiente: usabilidade e novas diretrizes. Educação ambiental em ação, 10(39).

Sirvinskas, L P. (2018). Manual de direito ambiental. (16a ed.), Saraiva educação.

Tupiassu, L., Gros-Desormaux, J. R., \& Da Cruz, G. A. C. (2017). Regularização fundiária e política ambiental: incongruências do cadastro ambiental rural no estado do Pará. Revista Brasileira de Políticas Públicas, 7(2), 188-20. 